\title{
Heráclito: la física de los contrarios
}

\author{
Ladislao Cuéllar \\ Departamento Académico de Filosofía
}

La física de Heráclito de Éfeso (540-475a.n.e.) continúa la de los jonios, es una cosmogonía fundada en un elemento cosmogónico: el fuego, pero, en

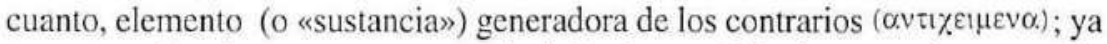
que no sería solamente como un símbolo de movilidad, concordante con la fórmula heraclítea: «todo fluye (rávtapei). «No es posible ingresar dos veces en el mismo río...»!'

Consideramos que en la física de Herâclito, la dialéctica es materialista ${ }^{2}$ y por ende científica; representa una primera manifestación de un materialismo dialéctico espontáneo, en el que la noción de medida está también manifiesta ${ }^{3}$. $\mathrm{Al}$ respecto, dice Abel Rey: «La precisión de esta FÍSICA de las cualidades de los contrarios, de esta física de las leyes que por los contrarios gobiernan los cambios cualitativos, va a ser buscada [...], en el rumbo de las medidas por los números [...], pero de thiabmårotrebien diferente quela nuestra hacia la canti-

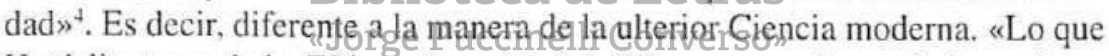
Heráclito toma de la Física griega del siglo VI, y por eso la continúa, es de un lado, todo lo que entra naturalmente en su doctrina del devenir, del flujo de las cosas ${ }^{5}$.

Fr. 9: de Plutarco, según la ordenación Diels-Kranz. (Tomado de la relación de fragmentos de Heráclito. transcrita por Mondolfo, en su Heráclito. Cf. Rodolfo Mondolfo. Herćclito. México. Ed. Siglo XXI 1960. pp. $30-47$.

2 Nota. En realidad. los primeros filósofos fueron monistas, $y$ cuando nosotros a posteriori los estamos tipificando de materialistas o idealistas: sólo estamos usando -metodológicamente- el planteamiento del problemn del «Ser y el pensar», según F. Engels. en su opúsculo: Ludwig Felierhach y el fin de la filosofía clásica alemana, cap. II.

Cfr. Fr. 30 de Clemente. según la ordenación de Diels-Kranz.

Abel Rey. La jurentid de la cienciat griega. p. 235.

Ihid..p. 238 .

Letras (Lima), 95-96: 135-142, 1998. 
La filosofía heráclitea es sometida a dura crítica, principalmente por Aristóteles, que no obstante su realismo, también estaba influido por una «dosis» de idealismo objetivo, y en diversos pasajes de su Filosofía Primera, se muestra contrario a la dialéctica materialista de Heráclito. Por ejemplo, cuando Aristóteles dice: "Ciertos filósofos pretenden que una misma cosa pueda ser y no ser, y que se pueda concebir simultáneamente los contrarios. Tal es la conclusión de la mayor parte de los físicos ${ }^{6}$. Declaraciones, que a nuestro entender, lejos de lograr una refutación, más bien le da una mayor unidad de principios a la FÍISICA o FILOSOFÍA de los primeros años. Luego, más adelante, el Estagirita señala: «El origen de esta opinión nace del cuadro que presentan las cosas sensibles. En primer lugar han concebido la opinión de la existencia simultánea en los seres, de los contradictorios y de los contrarios, porque veían la misma cosa producir los contrarios» ${ }^{7}$.

En efecto, Filón refiriéndose a la filosofía heraclítea, decía: «Lo que está hecho de contrarios es uno, y si lo uno se divide, los contrarios se manifiestan. Esto es precisamente lo que, según dicen los griegos, su grande y muy famoso Heráclito establecía como prefacio de su filosofía presentándola como la condensación completa y de cuyo descubrimiento se ufanaba» ${ }^{8}$. Reflexionando sobre esta crítica, comenta Rey: "Su descubrimiento, si, ya que la física reynante, la que expondrá Parménides, la de los pitagóricos, se hace estrictamente dualista. En los finales del siglo [IV], será hasta pluralista. Pero tiene sus preludios en los grandes monismos jonticos, en los monismos de Anaximandro y de Anaxímenes. Sólo quegenientraśenlAiraximandoes el efecto de la injusticia, en Heráclito es la justicia misma, porque es la ley. Lo real es a la vez uno y múltiple; los dos procesos de división y de unificación son simultáneos, al contrario que en la futura doctrina de Empédocles» ${ }^{9}$. Es decir, en el sentido de un alternarse, las fases de formación y destrucción del cosmos, tal como Aristóteles lo señala, tanto para Heráclito como para Empédocles.

\footnotetext{
- Aristóteles, Obras completas. Tomo II: Met. Lib. IV, cap. 4, p. 114.

? Ibid.. cap 5. p. 122.

s FILON de Alejandría (30 a.n.e.- 50 d.n.e) Rer div. Her., p. 43. Cf. A Rey. Op, cir, p. 239 (INFRA).

9. Abel Rey, La juventud de la ciencia griega, pp. 239-240.
} 


\section{LA CONFLAGRACIÓN CÓSMICA, EN HERÁCLITO}

El ilustre helenista, Rodolfo Mondolfo, refiere: «Según los testimonios de Aristóteles, considerados por E. Zeller, como declaraciones explícitas de la

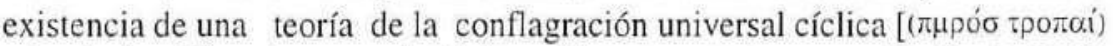
o la ekpirosis], en la cosmología heraclítea, se encuentran en De Caelo I, 10, 279b 12 y en Phys. III, 5,205 a [p. 377, en la trad. de González-Blanco], reproducido en Metph. 1067a [Lib. XI, cap. X] [...]. Aristóteles opone el principio universal (fuego) al cosmos engendrado por él mismo, diciendo que, según Heráclito, aquel se transforma en éste. Pero no dice que eso acontezca una sola vez $(\alpha \pi \alpha \zeta)$, sino repetidas veces ( $\pi \circ \tau)$. Ahora bien, una vez producida tal transformación, no podría repetirse si no interviniera la condición previa de la transformación inversa, esto, es el retorno del cosmos al principio universal. La re-

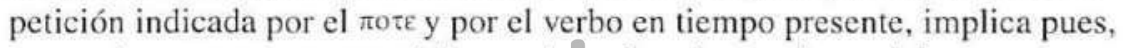
necesariamente un proceso cíclico; y si una fase de semejante ciclo compromete la totalidad del fuego, que deviene la totalidad del cosmos, la fase opuesta

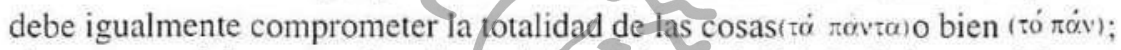
el cosmos o cielo que vuelve al principlo originario [...]. Aristóteles se adelanta, de todos modos, a los estoicosen atribuir a Heráclito la idea de la conflagración periódica del cosmos; y su indudable conocimiento directo del texto herácliteo otorga a este testimonio un peso innegable, ${ }^{10}$ concluye R. Mondolfo.

Consideramos, puéb, quie tąersion deI Estaginata, en el sentido de una alternacidad de fases, aømogla máscadecalda panareftejar el proceso de formación y «destrucción» del cosmos, y también por que sería - en cierto modoconcordante con la cosmología actual, ${ }^{11}$ vgr. con la teoría de la gran explosión (big-bang), y con el punto de vista que sostenemos sobre la posibilidad del universo cíclico. Lo cual no fue ajeno a las concepciones de los primeros filósofos, y muy particularmente a Heráclito e Hipaso de Metaponte; por ejemplo, cuando respecto al principio, dicen: «Del fuego nacen todas las cosas, y en el fuego todo termina. $\mathrm{Al}$ apagarse este, se engendran en ordenamiento cósmico, todas las cosas ${ }^{12}$. Son concepciones que trataremos de seguir interpretando, en algu-

Rodolfo Mondolfo, Hercictito. México, Ed. Siglo XX1. 1966, p. 124.

1. Pero, serín más preciso decir. que más bien, la cosmología actual se ha inspirado en la antigua, a pesar que los cientificos de la línea neo-positivista, tildan de metafísica a las especulaciones de los primeros filósofos físicos

1: AECIO I, 3.11 (en Doxographi graéci. p. 283), Cf. Testimonios doxográficos compilados, por R. Mondolfo en Hécáclito. p. 11.// En términos actuales diriamos que al ir bajando rápidamente la temperatura, surgen ordenadamente las diferentes eras del Universo, hasta llegar a la actual era de los átomos y moléculas. 
nos pasajes de la Parte II y especialmente en la Parte III (o Apéndice), pero, ya a la luz de la Física contemporánea ${ }^{13}$.

La hipótesis de la conflagración universal periódica, así como la idea de un Universo cíclico, en el que el fuego se convierte en la totalidad de las cosas y viceversa; nos demuestra que hay, pues, una cosmogonía en Heráclito. Además el conocido fragmento 30, también nos dice: «Este cosmos, uno mismo para todos los seres, no lo hizo ninguno de los dioses, ni de los hombres, sino que siempre ha sido, es y será fuego eternamente viviente que se enciende según medida y se apaga según medidas». Siendo éste fragmento una evidencia mas de la existencia de una cosmogonía conflagracionista en Heráclito; a la vez que encontramos en él, una clara referencia a la noción de medida, tan importante para la ciencia, porque involucra la cierta regularidad existente en los fenómenos y procesos naturales. Todo lo cual, nos remite a la hipótesis del «Gran año heracliteano», cuyo periodo -según Testimonio de Aecio-II, 32, 3 (Doxographi graeci, 364), era de 10,800 afios solares que son entendidos por Mondolfo y Zeller, como ciclo cósmico ${ }^{14}$. Este gran año heraclíteo, que -desde luego- no sería coincidente con el períođo que señala Heráclito; estaría conformado por un semi-ciclo ascendente o de rarefacción por expansión (esto es, actualmente detectable por el edrrimiento espectral hacia el rojo), y el otro semi-ciclo descendente o de condensación (que sería de corrimiento espectral hacia el azul). Lo cual, no consideramos que sea una apreciación descartable por anacronismo ni-exddtamente falsafanalogitra.s

\section{"Jorge Puccinelli Converso»}

Sin embargo, es menester tener siempre en cuenta, que el ópxí herácliteo; es eterno, pues la diversidad generada por el fuego, después de ser reducida a la Unidad, por el mismo poder del fuego que rige el Todo (tó $\pi \dot{v}$ ), a semejanza del ave Fenix, volvería a resurgir nuevamente, en cuanto «sistema universal» -analógicamente- a manera de infinitos bigs-bangs cíclicos. Pero, no nos confundamos: no es el «eterno retorno» el que estamos defendiendo, pues, las posibilidades de desarrollo de la materia son multifacéticas, y por lo tanto, no habría -precisamente- la misma yuxtaposición de la diversidad en cada ciclo.

En términos generales, diríamos que son los sistemas cósmicos, los que se destruyen en la llamada «justicia del logos heraclíteo», en consecuencia, el

\footnotetext{
1) Cf. L. Cuéllar. Fisica vo Filosofía Primera. Lima. Ediciones de la serie: "Una nueva filosofía", 1998 . pp.
289.295 y $338-343$.

it Cf. R. Mondolfo. Heráclito. pp. 20 y 258.
} 
universo actual, es finito, pero el principio generador -el fuego- permanecería a través de la multiplicidad de transformaciones de la diversidad, durante los infinitos ciclos cósmicos. En efecto, si algo existe, es porque ha estado existiendo y los actuales cosmólogos haciendo una retrodicción científica en base a la ley de Hubble, han calculado la edad del actual «sistema» universal, desde los inicios de su expansión (o ciclo ascendente, según el pensamiento antiguo), habiendo obtenido valores que van de los 12 a 15 mil millones de años, transcurridos desde su estado, super-denso o de comienzo de la estruendosa expansión (en otras palabras: en términos de la Física antigua sería: desde su Unidad esencial).

También con respecto a la conflagración periódica, el testimonio de Diógenes Laercio, sintetiza este proceso en la siguiente forma: «... El fuego es el elemento [universal] y todas las cosas son cambios del fuego ${ }^{15}$ que se engendra [todas] por rarefacción y condensadión [...]. Todas las cosas se engendran por oposiciones, $y$ todas fluyen amanera de ríos, el universo es finito, y existe un cosmos único que es engendrado por el fuego y consumido de nuevo por el fuego, alternadamente, en ciertos periodos en la totalidad del tiempo [o en la infinitud del tiempo, en otros doxógrafos]. Todo esto se produce [en Heráclito], según una necesidad fatal. Dedos contrarios: el que conduce al nacimiento, se llama guerra y discordia; el que eonduce a la conflagración se llama concordia y paz; y la transformación se llama camino hacia «arriba» y hacia «abajo» y conforme con este [doblepcanthoseqealiza el devenisdel cosmos» ${ }^{16}$.

\section{"Jorge Puccinelli Converso"}

En realidad, existe una predominancia de las tendencias idealistas, en la interpretación de la fillosofía heracliteana. En efecto, distinguidos helenólogos, partidarios de las concepciones socrático-platónicas, que desde sus inicios se opusieron a la Física; sólo tratan de ver en el gran Efesio, una teología, a la vez que critican a Aristóteles, por hacer de Heráclito un físico, que desde luego lo es, al igual que los demás filósofos pre-aristotélicos, continuadores de la Escuela jónica. Otros autores, lo consideran una personalidad mística, por haberse referido a la justicia y al castigo por el fuego. Pero es de suponer, que la justicia

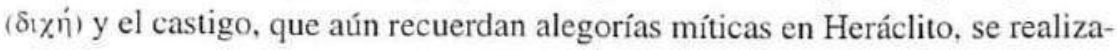

15. En efecto -en términos contemporáneos-podemos especular que la imagen del fuego representa -por analogía- los momentos cruciales, en que se intensificarían lo cambios cósmicos en la alta energía cinética de la Unidad de las cuatro fuerzas elementales de la Naturaleza: cuando la proto-materia super-densa pasa a ser energía (o viceversa) creándose la equivalencia einsteniana: $E=M c 2$, que rige para la materia convencional. así como para la anti-materia.

is Diógenes Laercio. IX, 1-17. Testimonios doxográficos compilados por R. Mondolfo. Heráclito, pp. 1-27. nro. 8 . 
ría a través de la propia necesidad natural ${ }^{17}$ y no en una transfísica. Es decir, cuando en el ciclo descendente de la conflagración cósmica, el Todo nuevamente retorne a su unidad sustancial: EL FUEGO. Así también, la doxografía transcribe, que según Aecio: «Heráclito al fuego que vuelve cíclicamente, lo llama eterno (Dios) y al destino le dice Razón creadora de los seres por el concurso de los opuestos» ${ }^{18}$.

En consecuencia; sin contrarios, no habría nada, ni armonía, pues, la guerra reina en el cosmos, al igual que entre los hombres: «la guerra es el padre de

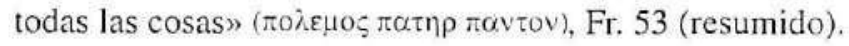

\section{FÍSICA, LOGOS Y ÉTICA EN HERÁCLITO}

Aunque las raíces del pensamiento heracliteano se hayan, pues, indisolublemente ligados a la problemática originaria de la Física de los milesios; sin embargo, según señala Mondolfo: «Reinhardt sostiene que la Física sólo le interesa a Heráclito, para resolverel problema lógico de los contrarios ${ }^{19}$. En efecto, vemos que Reinhardt -aparte de su oposición a la tradición aristotélica y doxográfica- hace una separación en la problemática, sin tener en cuenta que lo lógico, en su esencia ylo inicio, depende de la Physis ${ }^{20}$.

Analizando la interpretación de Otoe Gigeñ (Unters. Zu Herackl. 1935, pp. 455.; Der Urspr. d. griechp Bhilose19450pp 203655). R. Mondolfo, nos dice: «El Logos que Heráclito expone es la verdad, la clave de la comprensión de la realidad universal, la ley de la existencia cósmica» ${ }^{21}[\ldots]$. [Aparentemente] Heráclito desplaza el centro de la investigación, del problema milesio del prin-

17 La admisión de la casualidad, dentro de la propia necesidad natural, se da ya, posteriormente en Epicuro: perfeccionando asi a la Física jónica, de la predominancia mecanicista, aperturándose, a la vez la posibilidad de admisión de la libertad real.

18 AECIO. 1. 7.22 (Doxographi graeci, p. 303). Testimonios biográficos y doxográficos compendiados por $\mathrm{R}$. Mondolfo. Heráclito. p. 15.

19. Ihid. p. 140.

5o En un mundo (o planeta) alumbrado por dos "soles", distanciados por órbitas diferentes: los seres vivientes y las cosas reales tendrian dos sombras. En un mundo así, sería lógico decir: «tú no crees ni en tus sombras, o crees en una y en la otra nom, ;Lógico! diría el interlocutor. En ese supuesto planeta, todo ello sería necesario y por ende lógico o racional. Existió pues, una lógica natural, (que emanó de la propia realidad física). la cual se tornó, cada vez, más abstracta a través del trabajo y la comunicación social. Esto también. lo habia dado a entender Hegel, al señalar las relaciones entre lo real y lo racional.

21 R. Mondolfo. Herciclito, p. 136. 


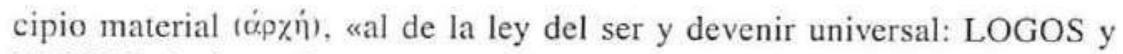
NOMOS al mismo tiempo, que por lo tanto, es también ley y criterio del pensamiento humano y gobierna igualmente tanto la vida del cosmos, como el obrar del hombre»"2. El maestro sanmarquino José Russo Delgado, nos refuerza la cita que precede, cuando dice: «Guthrie señala (HGP, I, 26), que según Kirk (HCF 396), para Heráclito «no había una rigurosa distinción cualitativa entre el Logos en cuanto contenido en una mente humana y el Logos que opera en la Naturaleza» ${ }^{23}$. Y, concluyendo su anterior párrafo, Mondolfo escribe: «Heráclito, vinculó así ética y cosmología como ningún otro [...], [Filósofo cosmólogo, prearistotélico]; conjugó en el concepto de Logos el problema cósmico con el lógico y moral: por eso Gigon lo considera el primero de los filósofos griegos que ha esbozado una ética en sentido estrictamente filosófico. Pero por otra parte, Gigon no descuida el hecho de que Heráclito, no obstante la diferenciación de su problema con el de los milesios, vincula, sin embargo, con el concepto de Logos la misma esencia física del FUEGO que se encuentra en infinita guerra consigo mismo y es él mismo inteligente, según Heraclitom ${ }^{24}$.

De todo lo expuesto se eselarece, que efectivamente, la ética heraclítea, al igual que la cosmología, estaba eomprendida en su física, esto es, sentando las bases de una primera ética cientiffica, con lo cual Heráclito proyectó todo una línea conceptual, que a continuación fue seguida -en cierto modo- por las es-

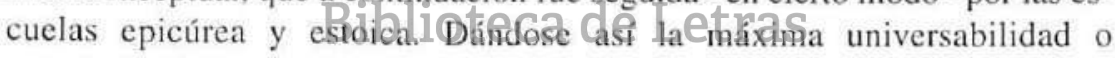
completitud a la físicaJantgeuQ,uencouahtiocotencer sofilosofía primera, que aristóteles no niega, sino que en primera instancia ha de constituir una continuidad y no una ruptura, como señalan algunos autores.

En conclusiones previas: vemos pues que la filosofía de Heráclito, no deja de ser una física, que encuentra en la lucha de los opuestos, la fuente del

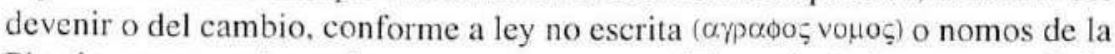
Physis, que es universal y eterna; pero que a diferencia de las normas de la

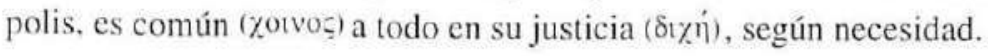

\footnotetext{
: Hid.p. 136

:Dr. José Antonio Russo Delgado. Herúclito, -Seminario de Filosofía Antigua- U.N.M.S.M. Ciudad Universitaria. Dpto. de Impresiones, 1974, p. 21.

: $\quad$ R. Mondolfo. Op. cit.. p. 136.
} 
A nuestro entender: el «Logos» de Heráclito es pues, ley y causa eficiente de los fenómenos cósmicos y humanos. En efecto, el logos heraclíteo, no se reduciría, pues, a una pura subjetividad humana; sino que en lo esencial, sería una cualidad general inherente a la Physis misma, y por lo tanto-dialécticamente-comprendería también el conocimiento de las leyes que operan en el gran todo y su Unidad.

Sentenciaba el gran Efesio: «No escuchando a mi, sino al Logos, sabio es que reconozcas que todas las cosas son Uno» ${ }^{25}$.

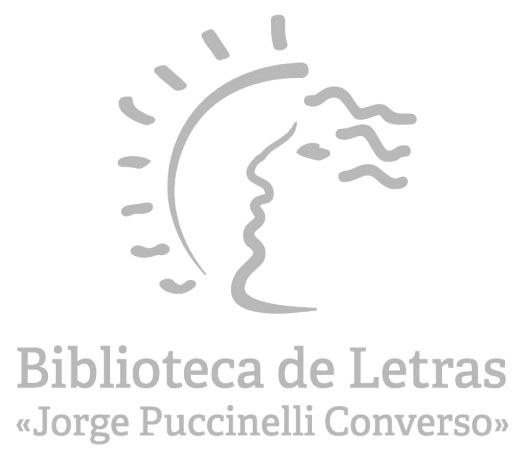

25. Heráclito, fg. 50, según la ordenación de Diels-Kranz. 